\title{
Review
}

\section{International spinal research trust research strategy. III: A discussion document}

\author{
M Adams ${ }^{1}$, T Carlstedt ${ }^{2}$, J Cavanagh ${ }^{1}$, RN Lemon*,3, R McKernan ${ }^{4}$, JV Priestley ${ }^{5}$, G Raisman ${ }^{6}$ and J Verhaagen $^{7}$ \\ ${ }^{1}$ Research Division, ISRT, Bramley Business Centre, Bramley, Guildford, Surrey, UK; ${ }^{2}$ Royal National Orthopaedic \\ ${ }_{5}^{T r u s t}$, Stanmore, UK; ${ }^{3}$ The Institute of Neurology, Queen Square, London, UK; ${ }^{4}$ Pfizer Limited, Sandwich, Kent, UK; \\ ${ }^{5}$ Neuroscience Centre, St Bartholomew's and the Royal London School of Medicine and Dentistry, London, UK; \\ ${ }^{6}$ Spinal Repair Unit, Institute of Neurology, Queen Square, London, UK; ${ }^{7}$ Netherlands Institute for Brain Research, \\ Amsterdam, The Netherlands
}

Study design: Discussion document.

Objectives/methods: To review the Research Strategy of the International Spinal Research Trust (ISRT), which identifies key areas of basic and clinical research that are likely to be beneficial in developing potential treatments for spinal cord injury for funding. This strategy is intended to both guide the programme of research towards areas of priority and stimulate discussion of the different avenues of research. This latest document has been developed to take into account the scientific progress in the 6 years since publication of the previous Research Strategy.

Results/discussion: The latest scientific developments in research designed to repair the spinal cord and restore function following injury and how they might impact on spinal cord injury research are highlighted.

Sponsored by: ISRT.

Spinal Cord (2007) 45, 2-14. doi:10.1038/sj.sc.3101963; published online 1 August 2006

Keywords: spinal cord injury; regeneration; ISRT

\section{Introduction}

The International Spinal Research Trust (ISRT) is committed to developing treatments to cure the consequences of spinal cord injury. For over 25 years it has pursued this goal by funding scientific research proposals from basic research scientists. More recently, it has recognised the need to improve the scientific basis for assessment of spinal cord injury in patients, and has committed funding to developing such techniques and training scientists in their use. It is intended that, when established, these measures will provide a resource for use in clinical trials worldwide, and will enhance the detection of functional repair and recovery in such trials.

The record of achievement of the ISRT in promoting basic and clinical research leading to potential treatments for spinal cord injury is second to none: it is the pre-eminent UK organisation in this area, and funds international research with a global impact.

*Correspondence: RN Lemon, Sobell Department of Neurophysiology, The Institute of Neurology, Queen Square, London WC1N 3BG, UK
Although by no means the largest funding organisation in this area, ISRT is consistently at the forefront of research in this field, and has developed an enviable reputation for 'punching above its weight' compared with larger organisations. Historically, one of the reasons for this is the ISRT Research Strategy, which has been developed by the Scientific Committee to identify and focus efforts in particular areas of research.

The first ISRT research strategy document was published in by Harper et al in 1996, ${ }^{1}$ and was refined and updated extensively in the second research strategy. ${ }^{2}$ These documents established a coherent research strategy by analysing specific areas that require attention in order to achieve the overall objectives of the ISRT - to repair the damaged spinal cord and restore useful function. The strategy documents identify key areas for funding and support, which enables basic and clinical researchers to focus research proposals, and the Scientific Committee and external reviewers to judge each proposal accordingly. This approach steers the programme of research to be steered towards areas of priority. In addition, the document has proved useful as a campaigning tool. 
The unprecedented success of spinal cord injury research in the past few years has resulted in significant advances, some of which were not covered by the previous research strategy. Consequently, ISRT have updated this document to reflect the current state of progress.

The following document, which identifies priorities for basic and clinical research in the coming years, builds on, and should be read in conjunction with, the existing research strategy. ${ }^{2}$ In general, ISRT expects applications for research funding to be influenced by and to refer directly to the themes described in this strategy document, but also recognise the need to incorporate novel approaches as they are developed.

In addition to promoting experimental and clinical studies, ISRT considers it vital to promote informed debate between basic scientists and clinicians on the merits, risks and scope for interventions in the aftermath of SCI that exploit existing anti-inflammatory, antiproliferative, neuroprotective and immunosuppressive drugs. This should include harnessing the insights and testing capabilities of existing large study groups worldwide, for example, via the International Campaign for Cures for Spinal Cord Paralysis (ICCP) Clinical Trials Workshops (http://www.campaignforcure.org), the European Clinical Trials Network (http://emsci.org) and the North American Clinical Trials Networks (http://www.christopherreeve.org/site/c.geIMLPOpGjF/ b.1048737/k.322D/North_American_Clinical_Trials Network_NACTN.htm) with a view to fostering wellfounded clinical best practice.

The targets that form the Third ISRT Research Strategy Document reflect current progress in spinal cord injury research. Many were highlighted in the earlier Research Strategy, whereas the importance of others has been recognised relatively recently. As previously, overall strategy is divided into two themes: the vertical targets represent experimental objectives and the horizontal capabilities indicate the means by which the vertical targets are likely to be fulfilled.

\section{Vertical targets}

- VT1. Early trauma/inflammation and scar tissue

- VT2. Inhibitory and facilitatory influences

- VT3. Guiding regrowth

- VT4. Spared spinal cord cells and fibres

- VT5. Cell- and gene-based therapies

- VT6. Combinatorial therapies

- VT7. Complementary therapies

\section{Horizontal capabilities}

- HC1. Animal models

- HC2. Measuring regrowth and restoration of connectivity

- HC3. Clinical trials

- HC4. Collaborative research

\section{Vertical target 1}

Minimising the deleterious effects of early trauma, inflammation and scar tissue

Much of the post-traumatic tissue damage and subsequent neurological deficits associated with SCI occur as a result of secondary events that are initiated by the original injury. Thus, spinal injuries comprise a primary zone of direct injury plus a zone of secondary injury, and neuroprotective strategies that either reduce or prevent the spread of secondary damage are likely to result in greater recovery of function. ${ }^{3-5}$ Many of the mechanisms responsible for these secondary processes remain unknown. Thus, further understanding of the detailed molecular and cellular mechanisms involved in early trauma and cell death, inflammation and glial scarring is vital to provide direction for the rational development of therapeutics to minimise secondary damage and enhance function following injury. This is the rationale behind treatments such as methylprednisolone, ${ }^{6}$ more experimental treatments such as GM-1 gangliosides (which also promote plasticity) ${ }^{7}$ and newer developments such as the tetracycline derivative minocycline. ${ }^{8}$

Spinal cord injury should not be regarded in isolation. There are similarities in the mechanisms of secondary cell death following ischaemic and traumatic brain injuries, ${ }^{9}$ and some potential therapeutics have already been tested in clinical trials of ischaemic brain injury. The lessons learned from these (relatively unsuccessful) trials should provide valuable information for the spinal cord injury community regarding clinical trial issues such as the need for controls and careful dose studies (see Horizontal capability 3). Therefore, in addition to developing new therapies, an important role of the ISRT is to promote informed debate between scientists and clinicians, and the critical evaluation of the merits of these existing and potential treatments (see Horizontal capability 4).

However, because most neuroprotective strategies have not had particularly substantial effects in clinical trials,${ }^{10}$ there is a high priority to increase the understanding of cell death after acute spinal injury and the conditions that develop in chronic injury (Table 1; VT1.1), in order to develop newer, more powerful therapies.

It remains important to characterise the effects of injury on major spinal cord components, such as the effects on grey matter and white matter, the composition and effects of the glial scar, vascular effects and the role of inflammatory responses, the extent and mechanisms of secondary cell death, and the factors that lead to cyst formation (Table 1; VT1.1). It is also important to characterise the contribution of these events to functional deficits (Table 1; VT1.2), and to accurately and meaningfully measure the effects of therapeutic agents on spinal cord function and behaviour. It should then be possible to develop novel neuroprotective therapies, both by rational mechanistic drug design and by screening drug libraries in appropriate models. To ensure the 
Table 1 Vertical target 1: Minimising the deleterious effects of early trauma, inflammation and scar formation

\begin{tabular}{ll}
\hline & \\
\hline VT1.1 & Fund the detailed molecular and cellular characterisation of postinjury trauma in animal models of \\
& acute and chronic SCI with particular attention to the consequences of different types of injury, the \\
effects on grey matter and white matter, the composition and effects of the glial scar, vascular effects \\
and the role of inflammation, the extent and mechanisms of secondary cell death, axonopathy and \\
axonal protection after trauma, and the factors that lead to cyst formation. Use this information to \\
promote research into reducing the deleterious effects of human injury.
\end{tabular}

Table 2 Vertical Target 2: Research into inhibitory and facilitatory molecules

\begin{tabular}{lll}
\hline & Action plans & Priority \\
\hline VT2.1 & $\begin{array}{l}\text { Support research that advances knowledge of how inhibitory and facilitatory molecules control axon } \\
\text { sprouting, growth and synaptogenisis, and examines the role and regulation of regeneration- }\end{array}$ \\
VT2.2 & $\begin{array}{l}\text { associated genes (RAGs) } \\
\text { Support research that defines factors that aim to promote regeneration by reducing inhibitory effects } \\
\text { VTd/or increasing facilitatory effects, or by manipulation of RAGs }\end{array}$ & $\begin{array}{l}\text { Support research that investigates how these effects relate to strategies of cell transplantation, which } \\
\text { provide anatomical pathways for regenerating axons }\end{array}$ \\
\hline
\end{tabular}

validity of such models, it is also necessary to further our understanding of human spinal injury (Table 1; VT1.3), and to identify accessible markers of early traumatic injury in humans (Table 1; VT1.4).

\section{Exclusions and future issues}

Work in non-spinal cord models should be explicitly justified. Funding for the acquisition of new therapeutic approaches to tackle inflammation etc. outside the spinal cord, for use in SCI research, will be considered under this strand of the Strategy and within Horizontal capability 4.

\section{Vertical target 2}

\section{Inhibitory and facilitatory molecules}

The inhibitory effects of the CNS on axon growth are well documented, as is the ability of peripheral nerve grafts to support regeneration. The consensus is that there are several possible reasons why peripheral nerve grafts support CNS regeneration. The first is that inhibitory cues that are present in the CNS are absent from the PNS. The second is that peripheral nerve grafts secrete neurotrophic factors and contain other regeneration-promoting proteins such as cell-surface proteins that overcome CNS inhibition. A third possibility is that inhibitors that are present in PNS grafts are localised and regulated in a way that allows regeneration. Thus, it is established that chondroitin sulphate proteoglycans (CSPGs), some myelin proteins and semaphorins are present in both the PNS and the CNS, but their expression, stability and localisation/cellular distribution are different. Moreover, some types of CNS neurons do not grow into peripheral transplants. ${ }^{11}$ This may be because of the presence of inhibitors in the grafts, or because these CNS neurons are unable to mount an appropriate response of regeneration-associated genes (RAGs).

Therefore, research into inhibitory and facilitatory molecules falls into three categories: the discovery of molecules that contribute to inhibition and facilitation of axon growth (Table 2; VT2.1), the production of reagents that either counteract inhibition or increase facilitation (Table 2; VT2.2), and the investigation of how other approaches, such as cell- and gene-based therapies, interact with inhibitory/facilitatory molecular mechanisms (Table 2; VT2.3).

The idea that the presence of inhibitory molecules causes regeneration failure was proposed by Schwab and collaborators, first in culture ${ }^{12}$ and then in the injured spinal cord, ${ }^{13}$ on the basis of a molecule present on the surface of oligodendrocytic myelin. ${ }^{14}$ This molecule is now known as Nogo. Blocking Nogo promotes either regeneration ${ }^{13}$ or beneficial sprouting. ${ }^{15}$

Nogo is one of several inhibitory molecules that are associated with CNS myelin, with other candidates including myelin-associated glycoprotein and oligoden- 
drocyte myelin glycoprotein. Subsequently, inhibitory molecules of the CSPG, ephrin and semaphorin families have been found to be associated with astrocytes and fibroblasts ${ }^{16-20}$ and a common pathway for the effects of these various inhibitory molecules has been described. ${ }^{21}$ It is likely that increased molecular characterisation of this common inhibitory pathway will help in the development of new therapies.

In addition to the lack of inhibitory molecules, it is proposed that peripheral nerve grafts support CNS axon regeneration by the secretion of trophic factors. Many studies have shown that growth factors upregulate RAGs and enhance regenerative axon growth, ${ }^{22-24}$ and genetically modifying transplants to overexpress neurotrophic factors might enhance these effects further. Thus, an effective combination that enhances positive factors and reduces negative ones is an attractive goal for current research.

So far the molecular response to neural injury has been studied mainly at the level of changes in the expression of single genes or proteins. This has led to the discovery of several molecules that are important in regeneration. The human and rodent genome projects have identified most human and rodent genes. This enables high-throughput screening of large cohorts of genes and proteins, which will be instrumental for elucidating the molecular mechanisms that underlie regenerative failure and should result in a more complete picture of the molecular changes that occur in neurons and glial cells after injury. ${ }^{25}$ The use of microarrays and of proteomic techniques coupled to web-based databases and data-analysis tools is likely to identify previously unknown RAGs, and to pinpoint novel targets for pharmacological and cell- and genebased intervention strategies. Our understanding of the molecular processes that underlie regeneration is still very limited, so incorporating genomic and proteomic approaches into neuroregeneration research is vital to progress in this field.

\section{Vertical target 3}

\section{Guiding regrowth and establishing appropriate connections}

Several existing therapies promote the regeneration of injured axons in long, white-matter pathways. In addition, methods are being developed to bridge spinal injury sites using synthetic biomaterial implants. ${ }^{26,27}$ However encouraging axons to leave the special environment that these therapies provide, to cross scar tissue associated with the injury area, and to re-enter the tissue beyond the scar has proved a major problem.

Given that the number of axons that do regenerate and regrow is likely to be small compared with the original pathway, it is important to understand how fibres behave once they have reconnected with the spinal cord beyond the damaged area. At one extreme, it might not be necessary to guide regrowing fibres to their appropriate targets if intrinsic, plastic mechanisms within the CNS can exploit any connectivity to achieve some recovery of function. At the other extreme, new connections might be either ineffective or even add to secondary problems such as spasticity and increased pain levels. We are acquiring a detailed map of factors that guide axons to their eventual target by attraction and repulsion, including factors that keep axons in long white-matter tracts until they descend (or ascend) to the level appropriate to penetrate the grey matter. ${ }^{28-30}$ Once within the spinal grey matter, ephrins, netrins, semaphorins and related molecules guide axons and regulate midline crossing and dorso-ventral termination.

It is probable that the main national research funding bodies will continue to invest in this area of basic neurobiology, thereby expanding the 'library' of agents that guide growing and regrowing axons. ISRT should adopt a strategy of integrating this knowledge into spinal injury studies and promote research into:

- The nature and temporal course of new synaptic connectivity after SCI, using histological and electrophysiological techniques (Table 3; VT3.2).

- The key guidance/trophic factors - how they are affected by SCI, particularly in regions above and below the site of injury (Table 3; VT3.1, VT3.2), and whether their expression can be modified to encourage appropriate outgrowth (Table 3; VT3.3).

- The potential of axonal sprouting and synaptic plasticity for regeneration and useful re-innervation (Table 3; VT3.3).

- The ability of trophic factors to restore axonal growth per se and to influence the re-establishment of appropriate connectivity (Table 3; VT3.4).

\section{Vertical target 4}

\section{Assessing the natural history of SCI and optimising} spared spinal cord cells and nerve fibres

Except for a few open or penetrating injuries, there is spared spinal cord tissue in most cases of SCI, even if clinically the lesion is complete. Tissue sparing has important consequences, both in terms of the function of the residual axons and their potential for plasticity. In animal models, fibres passing through the ventrolateral funiculi, including reticulospinal axons, appear to be important for functional recovery of hindlimb locomotor function. ${ }^{31}$ In humans, the importance of the ventrolateral systems is less clear, while damage to corticospinal fibres has more serious effects. ${ }^{32}$

The minimal sparing of white matter, in terms of either area or axonal number, that is compatible with locomotion is $\sim 10 \%$ for cats, ${ }^{33}<25 \%$ for non-human primates $^{34}$ and $<10 \%$ for humans. ${ }^{35}$ Minimal deliberate movement of the lower limb, including dorsal and plantar flexion of the foot, has been reported in humans with only $3.5-10 \%$ of corticospinal tract axons at the thoracic level. ${ }^{35}$ The idea that a limited number of nerve fibres is sufficient for function has encouraged repairbased research, and has been formulated in the belief 
Table 3 Vertical Target 3: Guiding regrowth and establishing appropriate connections

\begin{tabular}{ll}
\hline & \\
\hline VT3.1 & $\begin{array}{l}\text { Fund research to identify, quantify and profile the significant trophic influences on axonal regrowth } \\
\text { and connectivity pertinent to the damaged/regenerating spinal cord }\end{array}$ \\
VT3.2 & $\begin{array}{l}\text { Fund research that delineates the effects and the time profile of different patterns/sites of SCI on } \\
\text { axonal sprouting and synaptic circuitry, and the key trophic influences }\end{array}$ \\
VT3.3 & $\begin{array}{l}\text { Fund research into the cellular sources and regulatory mechanisms that govern the biosynthesis of } \\
\text { key trophic/guiding influences on spinal cord regeneration, and direct means of manipulating these } \\
\text { mechanisms to promote axonal regrowth after SCI }\end{array}$ \\
FT3.4 & $\begin{array}{l}\text { Fund research that uses well-defined functional outcome measures, such as locomotion, reach/grasp } \\
\text { and breathing, to determine whether these trophic influences and their manipulation are key to } \\
\text { re-establishing appropriate connections }\end{array}$ \\
\hline
\end{tabular}

that a few new axons that cross the lesion site and connect somewhere will result in some functional recovery.

After total spinal cord transection in laboratory animals, weight-supported, unassisted stepping can be generated by the spinal circuitry below the level of the transection, without supraspinal control. ${ }^{11}$ This is not the case in humans, but more lumbar motorneurons pools can be activated by proprioceptive sensory inputs generated by treadmill exercise than by voluntary activity in cases of incomplete SCI. ${ }^{36}$ The surviving supraspinal motor input to the spinal cord is insufficient to selectively activate specific muscles of a single joint or to simultaneously inhibit antagonist muscles, which indicates that voluntarily exerted force is only partially related to function. ${ }^{37}$ After complete SCI, it appears that local, segmental, proprioceptor motor circuits can be induced to generate patterned muscle activity, but not in a sustained manner. ${ }^{36,38}$

In animals and humans, plasticity in the motor systems has been shown at different levels from the cortex to the target muscle. ${ }^{39}$ Erroneous connections made after an injury persist for many years. ${ }^{40,41}$ Early after the injury there will be vacant synaptic sites that might be occupied by either inappropriate supraspinal tract axons or local interneurons. This plasticity is likely to account for the development and establishment of aberrant reflexes that might be counterproductive in either maintaining or supporting function, for example, spasticity or aberrant reflexes. In addition, the occupation of these sites by 'inappropriate' fibre systems might prevent appropriate regenerating fibre systems reconnecting to the right circuits. One way to prevent this might be the use of specific neuromodulatory treatments. The development of techniques that maintain the neuronal tissue below the level of the lesion as far as possible within its 'normal' state, and thereby prepare this tissue for successful interventions, should be encouraged.

Plasticity in the sensory systems, such as collateral sprouting, is well known and might account for phenomena such as the spread of sensation below the level of the lesion and the development of neuropathic pain. Imaging studies have shown that referral of sensation after SCI is accompanied by reorganisation of the somato-sensory cortex. ${ }^{42,43}$ However, this mechanism might not explain referred sensation from the viscera perceived in deafferentated areas. Nevertheless, large-scale reorganisation may occur at other CNS sites such as thalamus, brain stem, cuneate nucleus and spinal cord. ${ }^{44}$ This might include both unmasking of pre-existing connections ${ }^{48}$ and actual axonal sprouting. ${ }^{49}$ To achieve functional recovery of sensation after SCI, measures to be considered include manipulating the biological environment to promote regeneration and functional reconnection, and identifying strategies that increase reorganisation in the CNS.

It is important to define the structure and function of the remaining spinal cord tissue (Table 4; VT4.1), and to develop ways to enhance its functional capacity most effectively (Table 4; VT4.2, VT4.3). The clinical consequences of the neuronal loss at above and below the lesion site compared with damage to long fibre systems remains to be established. This knowledge is essential if treatments that are designed to replace lost neurons are to be considered alongside those that lead to repair of white matter tracts. Even if nonfunctional, remaining tissue might have a valuable role in the effects of future interventions by either guiding or acting as a scaffold for new growth.

\section{Vertical target 5}

\section{Cell- and gene-based therapies}

Since the last strategy review in $2000,{ }^{2}$ major progress has been made in the areas of cell and gene therapy. Cellbased therapy includes grafting with fully differentiated tissue such as peripheral nerves, inflammatory system cells such as activated macrophages, CNS-resident cells such as oligodendrocytes and olfactory ensheathing cells, and cell precursors such as stem cells. Stem cells are attractive theoretically because it is envisioned that they will respond to cues and replace damaged tissue, as in other organ systems, such as the foetal liver following injury and adult heart tissue after cardiac infarct. However, undifferentiated embryonic stem cells are less appropriate because they can develop into cancerous teratomas. Therefore, more differentiated cells and tissue of both foetal and adult neural origin are preferred 
Table 4 Vertical target 4: Assessing the natural history of SCI and optimising spared spinal cord cells and nerve fibres

\begin{tabular}{ll}
\hline VT4.1 & Establish reliable, baseline, postinjury data using invasive and noninvasive techniques \\
VT4.2 & $\begin{array}{l}\text { Develop techniques to determine if interventions modulate the function of surviving spinal cord } \\
\text { tissue }\end{array}$ \\
VT4.3 & Fund research to enhance and modify the function of spared connections \\
VT4.4 & $\begin{array}{l}\text { Fund the development of techniques to reduce unwanted effects, such as co-contraction, spasticity } \\
\text { and neuropathic pain by neuromodulation and other strategies }\end{array}$ \\
\hline
\end{tabular}

currently. Gene-based therapies have been developed in which either a therapeutic gene is expressed directly in the injured spinal cord or neural transplants are genetically modified before transplantation.

Cell-based therapies Cell-based therapies might act in several, distinct ways: (i) as a potential source of either trophic or growth factors that support and improve the function of pre-existing spinal cord neurons; (ii) transplanted stem cells might develop into oligodendrocytes and remyelinate regenerating axons; (iii) transplanted stem cells might develop into functional spinal cord neurons and directly replace those damaged by injury; and (iv) transplanted cells can serve as a substrate to support axonal growth. It is not clear which mechanisms predominate in studies that have reported restoration of spinal cord function and it might well be that different cell types act in different ways. The use of cells as a source of multiple trophic factors to provide the appropriate developmental niche for neuronal regeneration impacts on Vertical targets 2-4.

There has been some work to identify the cell types that are generated in vivo after stem cell transplantation. In vitro, undifferentiated, neurospheres in culture can generate all types of neural cell. However, although adult neural progenitor cells survive when grafted into the rat spinal cord, they only differentiate into astroand oligodendroglial lineages, which indicates that the adult spinal cord provides the molecular cues for glial, but not neuronal, differentiation. ${ }^{50,51}$ If neuronal cells are required, procedures for differentiating, isolating and transplanting them need to be perfected. Disappointingly, in some studies, transplanting neural stem cells leads to an increase in pain levels (allodynia), which is associated with sprouting of sensory fibres in the spinal cord. However, forcing stem cells into a distinct lineage before transplantation avoids allodynia and improves functional outcome. ${ }^{52}$ The benefits of grafting differentiated, purified cells require further study. These data indicate that care should be taken that preclinical studies should specifically examine the adverse effects of cell therapies.

Cell-based therapies require that the cells are readily obtainable, easy to expand and bank, and survive long enough to facilitate sufficient and appropriate axonal repair. Until large-scale, well-characterised adult and differentiated, embryonic stem cells are available, bone marrow mesenchymal stem cells (MSCs) are an attractive source that allows autologous grafting in which each subject receives their own bone marrow. Transplanted unpurified MSCs improve remyelination ${ }^{53}$ and support host axonal growth after spinal cord injury, and several studies achieve modest functional recovery. ${ }^{54-56}$ Differentiation into defined cell types such as Schwann cells might further improve the outcome, ${ }^{57}$ as might selection of MSCs from different donors because not all donors produce similarly effective cells, presumably because of the repertoire of cytokines and modulatory molecules that they produce. ${ }^{58}$

An alternative source of adult transplantable cells with repair potential are olfactory ensheathing cells. ${ }^{59}$ Two types of cells are generated from cultures of primary olfactory tissue: although both are essential for the reparative effect, the precise lineage relationship of the two cell types is not fully understood. ${ }^{60}$ Olfactory ensheathing cells encourage axonal growth in the spinal cord. However, they are likely to be more effective when combined with other treatments (see vertical target). For example, reducing inhibitory cues of the scar tissue with chondroitinase ABC and providing a Schwann cell bridge in combination with olfactory ensheathing cells promotes greater functional recovery in a rat model than these treatments individually. ${ }^{61}$

Gene therapy The first viral vectors used to express a therapeutic gene in the nervous system were imperfect because they evoked an immune response. These problems inspired the development of improved 'minimal' vectors based on adeno-associated virus and lentivirus. These viral vectors carry a transgene under a strong viral or cellular promotor, but are virtually devoid of viral gene sequences. Adeno-associated viralvector-mediated expression of neurotrophins has been successful in rescuing motor neurons after ventral root avulsion and reversing atrophy of chronically lesioned rubrospinal neurons. ${ }^{62,63}$ In addition to direct viralvector-mediated gene transfer, cellular transplants have been genetically modified ex vivo before transplantation to create improved cellular nerve guides. The steady advances made in combining new viral vector systems with a range of promising cellular platforms (see above) holds fascinating perspectives for the development of new spinal cord repair strategies (reviewed by Ruitenberg et $\left.a l^{64}\right)$.

Although there has been much progress in the area of cell therapy, significant questions remain (Table 5). The areas to be tackled in gene therapy are: (i) how to enhance the level of expression of the transgene; 
Table 5 Vertical target 5: Cell- and gene-based therapies

\begin{tabular}{|c|c|c|}
\hline & & Priority \\
\hline VT5.1 & $\begin{array}{l}\text { Determine which cell types are most effective in restoring defined spinal cord functions such as } \\
\text { myelin repair, segmental plasticity and regeneration, and how to generate a usable, expandable } \\
\text { source of these cells }\end{array}$ & High \\
\hline VT5.2 & Determine how much differentiation is required in vitro before transplantation & High \\
\hline VT5.3 & $\begin{array}{l}\text { Fund research into developing improved markers to study cell transplantation, especially those that } \\
\text { are compatible with noninvasive imaging techniques }\end{array}$ & High \\
\hline VT5.4 & $\begin{array}{l}\text { Determine the optimal timing of delivery and spatial distribution of transplanted cells, and the } \\
\text { number of cells required for successful repair }\end{array}$ & High \\
\hline VT5.5 & Develop and optimise viral vector systems and matrices for use in SCI repair strategies & High \\
\hline
\end{tabular}

Table 6 Vertical Target 6: Combining therapies

\begin{tabular}{ll}
\hline VT6.1 & $\begin{array}{l}\text { Fund the study of the combination of well-defined unitherapies in highly reproducible injury models } \\
\text { that are relevant to human SCI } \\
\text { Determine whether optimal improvement requires that cell-based therapies are administered in } \\
\text { conjunction with either trophic factors or anti-inhibitory molecules }\end{array}$ \\
\hline
\end{tabular}

(ii) control of the timing of transgene expression; (iii) the difficulty in predicting and controlling the cell types that are transduced, and some cells and tissues are easier to transduce then others (eg scar tissue can hardly be transduced for, as yet, unknown reasons); and (iv) the use of viral vectors to express siRNA and dominantnegative proteins to overcome local action of inhibitory proteins is in its infancy. Nevertheless, gene therapy is a powerful technique that might be used to overcome inhibition and to enhance the expression of neurotrophic factors.

\section{Vertical target 6}

\section{Combining therapies}

Several independent mechanisms contribute to the outcome of SCI. Therefore, it seems reasonable to anticipate that therapies that are directed at one specific injury mechanism are likely to have limited overall efficacy, and that combining potential therapies might achieve a greater benefit and increase recovery. ${ }^{61}$ Some published studies have combined the use of cell transplantation and plasticity-promoting drugs to provide proof-of-principle of this concept. It is likely that more effective combinations are possible, and combination therapy is likely to be a cornerstone of future strategies following SCI. However, because of potential interactions between different interactions, interpreting the effect of combining potential treatments requires very careful controls.

The potential complementarity of different therapies is crucial, and funding will only be considered for proposals that make a cogent case for combining individual approaches (Table 6).

\section{Vertical target 7}

The complementary role of different forms of electrotherapy for recovery of function after SCI

The aims of ISRT is to develop a long-term, effective treatment for SCI, based on better understanding of the underlying neurobiological mechanisms of injury and repair. Originally, therefore, functional electrical stimulation (FES), other forms of electrotherapy and intensive physiotherapy were not considered central to the research strategy because they were judged not to involve actual repair of the injury. However, in the past few years ISRT and the SCI community in general have re-assessed this position.

The primary purpose of FES is to activate paralysed groups of muscles; for example, FES implants are widely used for bladder control and to assist standing, locomotion and hand grasp. However, it is clear that, in addition to these 'peripheral' actions, FES also has long-term 'secondary' effects on central sensorimotor mechanisms ${ }^{65,66}$ that affect plasticity and, possibly, allows surviving fibres to make a greater contribution (see Vertical target 4).

A related point is that the development of the normal spinal cord and, probably, regeneration of the damaged spinal cord are, at least in part, activity-dependent processes; electrotherapy methods can be used to promote neural activity, above and below the injury, which cannot be generated voluntarily by the patient. Finally, we know that activity in the 'intact' parts of the motor network above the level of the spinal injury, including the cerebral motor areas, cerebellum and basal ganglia are significantly reduced after SCI and show different patterns during both attempted and imagined movements. Thus, FES, rTMS and other 
forms of electrotherapy might all complement other, more invasive therapies and boost therapeutic effects of intensive physiotherapy (Table 7).

Some forms of FES are invasive (eg sacral or lumbar root stimulators and intraspinal microstimulation) and some SCI patients refuse such implants because they expect a more permanent cure to be developed in the future and do not want to prejudice their chances of inclusion in future trials and treatment.

Given that the principal aim of ISRT is a long-term treatment that provides effective repair of SCI, how should it approach the development of FES and other electrotherapeutic approaches? ISRT should promote research into:

- Approaches that demonstrate the complementary role of FES in improving outcome of other types of treatment through activity-dependent plasticity.

- Studies to determine the extent to which defined FES paradigms improve real-world tasks that are highly relevant to individuals with SCI.

- The use of noninvasive methods that offer clear prospects of functional recovery, especially if such approaches improve central activity-dependent plasticity.

- Improved outcome measures to assess functional improvements provoked by noninvasive methods.

- The development of long-term, stable, electrotherapy techniques that complement other therapies for SCI.

\section{Horizontal capability 1}

Animal models

Effective experimental models are crucial for understanding the basic biology of SCI and developing effective therapeutic strategies (Table 8). Two common approaches are to use (i) a model that aims to mimic as closely as possible the type of SCI that is observed clinically (ie contusion injuries), and (ii) a model in which specific tracts or pathways are lesioned to study the response of that particular system to injury and its capacity for regeneration. Both approaches have their benefits and drawbacks, and potential treatments should be evaluated in both before they are developed for use in humans. Transection of the spinal cord is a recognised animal injury model, whereas contusion represents the typical injury mechanism in humans. A contusion injury extends over $2-3$ segments, which greatly exceeds the extent of neuronal damage in the transected spinal cord. Although the extensive damage and loss of alphamotoneurons and roots associated with spinal cord contusion is little addressed in current translational studies (see Vertical target 4), it has direct implications for rehabilitation strategies and functional outcome. There is also increasing evidence for degradation of neuronal function below the level of lesion in chronic, complete SCI ${ }^{38}$ The relevance of this degradation for a regeneration-inducing therapy needs to be evaluated. In addition, the prerequisites to facilitate the appropriate reconnection of regenerating tract fibres and to maintain neuronal function in the postacute stage have still to be established (see Vertical target 3).

Although the majority of SCI studies to date have involved rats, genomic approaches are carried out almost entirely in mice. Thus, the development of a mouse model of SCI had priority in the 2nd ISRT strategy document. ${ }^{2}$ Now such models are available, the use of knockout and transgenic mice is likely to provide insights into the molecular components of SCI and repair.

Table 7 Vertical target 7: The complementary role of different forms of electrotherapy for recovery of function after SCI

\begin{tabular}{ll}
\hline VT7.1 & $\begin{array}{l}\text { Fund research to investigate the effects of noninvasive methods of electrotherapy, including FES and } \\
\text { rTMS, on functional recovery after SCI, particularly those that complement other therapeutic } \\
\text { approaches }\end{array}$ \\
VT7.2 & $\begin{array}{l}\text { Fund research into understanding the mechanisms that mediate improvement by such methods that } \\
\text { are directly relevant to recovery from SCI }\end{array}$ \\
VT7.4 & Fund research into developing more stable invasive methods of applying electrotherapy to SCI \\
\hline
\end{tabular}

Table 8 Horizontal capability 1: Animal models

\begin{tabular}{|c|c|}
\hline $\mathrm{HC} 1.1$ & $\begin{array}{l}\text { Define specific types of SCI model that are suitable for investigating the potential therapeutic effects of various } \\
\text { compounds, drugs, interventions and treatments }\end{array}$ \\
\hline $\mathrm{HC} 1.2$ & Fund studies that attempt to adjust the insights generated from animal models to the scale and complexity of human SCI \\
\hline $\mathrm{HC} 1.3$ & $\begin{array}{l}\text { Fund work, both experimental and literature review, that integrates the results from different methodologies and } \\
\text { models, including the resolution of any discrepancies or gaps in existing knowledge }\end{array}$ \\
\hline $\mathrm{HC} 1.4$ & $\begin{array}{l}\text { Encourage the use of genetically modified animals (eg knockout and transgenic animals) in established SCI models } \\
\text { to gain additional insights into the key molecular and cellular components of SCI and its repair }\end{array}$ \\
\hline $\mathrm{HC} 1.5$ & Fund research into the significance of demyelination and remyelination in SCI and repair \\
\hline $\mathrm{HC} 1.6$ & $\begin{array}{l}\text { Fund research to establish a large-animal model of SCI in order to harness the sophisticated electrophysiological } \\
\text { capabilities available for this species }\end{array}$ \\
\hline $\mathrm{HC} 1.7$ & Fund the supply of equipment necessary for the standardised use of selected models in laboratories funded by ISRT \\
\hline
\end{tabular}


In each laboratory species used, the requirements of an animal model are that it is quantitative, robust, objective and leads to permanent records that are open and available to other researchers. The results obtained with a particular model must be reproducible when used independently by other research teams.

Ideally, experiments should have a sequential design that includes:

- Longitudinal observation of the behaviour in normal animals to establish the level of variation within the population and stabilise learning curves.

- Longitudinal observations of the same parameters after lesion to establish the degree of variation in the lesion procedure and the natural history and evolution of postlesional changes that occur without any intervention.

- The therapeutic intervention should be applied only when the postlesional situation is stable, and further longitudinal assessment carried out as above.

- Variation must be related to the normal population variation. Postlesional variation should correlate with individual histology because animals cannot be assumed to be uniform, and correlation with the lesion histology gives information about the size and location of the lesions that are associated with specific effects. In addition, posttherapeutic variation should correlate with individual variation in histological parameters of recovery (eg number of fibres regenerating and size of transplants), which should give valuable additional information.

\section{Horizontal capability 2}

Developing methods to measure regrowth and restoration of function

The ability to determine accurately the extent of anatomical regeneration, physiological connectivity and functional improvement is crucial for identifying a successful repair strategy. The current lack of reliable assessments of the extent of SCI in humans, and the spontaneous and treatment-induced recovery in laboratory animals and humans are fundamental problems for both basic science and potential clinical trials for SCI (see Vertical target 4).

The American Spinal Injuries Association (ASIA) score is not always fully reliable. For example, recent studies by Craggs and co-workers ${ }^{67,68}$ demonstrate that some patients who are classified as ASIA A (complete SCI) can voluntarily modulate the integrated EMG with pudendo-anal reflex (PAR). This sacral reflex is modulated by either voluntary or supraspinal centres and is a sensitive measure of spinal cord injury. ${ }^{69}$ Measuring improvements in the PAR and similar systems might provide a means to monitor progressive, postinjury changes in function, and outcome measures for future interventional treatments.

Methods to detect the partial preservation of long fibre tracts are also needed because present tests (eg the
ASIA sensory score) are unable to detect subtle neurological improvements. Assessments that reflect the whole clinical picture, such as the impact of spasticity, are also needed (Table 9). Although spasticity is useful for some abilities such as transfers, it frequently impairs functional outcome for the patient.

To some extent neurophysiological and functional assessments can differentiate between the contributions made by behavioural compensation, neuronal plasticity and regeneration to improvement of function following SCI. ${ }^{70}$ Neurophysiological investigations, in particular, should give information about the impact of any new interventional therapy on the function of specific spinal tracts and of the peripheral nervous system.

Most patients recover significant function without intervention, and deterioration of SCI patients after hospitalisation is relatively uncommon. ${ }^{71}$ For example, most quadriplegic patients recover one spinal level of motor function. ${ }^{3}$ However, following incomplete SCI, it is difficult to predict the preservation of discrete longitudinal fibre tracts and the likelihood of natural, spontaneous recovery of sensory and motor function. Difficulty in distinguishing between post-treatment improvements in function and changes that might occur without intervention creates potential problems for interpreting the results of clinical trials. Thus, it is apparent that new techniques are needed to assess more effectively spinal cord tissue that is spared after clinically complete and incomplete SCI, and to predict accurately any spontaneous recovery of function ${ }^{37}$ (Table 9). Collection at multiple injury centres of clinical and physiological data mapping the natural history of changes in function in the period immediately after $\mathrm{SCI}$ is, therefore, a priority.

Imaging the site of injury, for example, by MRI can indicate continuity across a lesion but does not reveal whether the axons are functional. Currently, electrophysiological assessments of sensory and motor tract function (eg somatosensory evoked potentials) indicate the presence of large, myelinated fibres in the dorsal columns but not finer fibres in, for example, the spinothalamic tract, and recovering or remyelinating fibres. Therefore, ways to identify different fibre tracts are needed. These might include intraspinal electrodes, which recognise unique patterns of activity in discrete fibre tracts. Functional imaging techniques should also be developed, and it is likely that the combination of functional imaging with selective stimulation and recording of fine fibre afferent pathways through, for example, contact-heat-evoked-potential stimulation of $\mathrm{C}$ and $\mathrm{A}$ delta fibres ${ }^{72}$ will provide more detailed analysis of baseline and functional improvements from interventions.

\section{Horizontal capability 3}

\section{Clinical trials}

The many issues that surround optimisation of Clinical Trials of SCI treatments were discussed at the recent ICCP International Clinical Trials Workshop on SCI. ${ }^{73}$ 
Table 9 Horizontal capability 2: Developing methods for measuring regrowth and restoration of function

\begin{tabular}{|c|c|}
\hline HC2.1 & $\begin{array}{l}\text { Fund research to develop the utility of noninvasive methodologies, including imaging and spectroscopy, for } \\
\text { assessing SCI and repair/regeneration in humans }\end{array}$ \\
\hline $\mathrm{HC} 2.2$ & $\begin{array}{l}\text { Fund studies to compare and delineate robust experimental methodologies to distinguish true CNS axonal } \\
\text { regeneration from collateral sprouting, surviving fibres, central rewiring and other mechanisms that might explain } \\
\text { recovered function or morphological evidence of new outgrowth }\end{array}$ \\
\hline $\mathrm{HC} 2.3$ & $\begin{array}{l}\text { Fund studies that develop new approaches to selectively labelling defined axonal tracts to facilitate subsequent } \\
\text { analyses of regeneration after SCI (eg by tract-specific transfection of neuronal populations with traceable markers) }\end{array}$ \\
\hline $\mathrm{HC} 2.4$ & $\begin{array}{l}\text { Fund work to develop functional assessment systems and parameters that offer objective, quantitative and high- } \\
\text { resolution information about re-innervation, to replace methods that measure changes in broad functions } \\
\text { (eg stepping systems) that could arise from multiple possible re-innervation/collateral sprouting/synaptic plasticity } \\
\text { mechanisms. Work should eventually be confirmed in a large-animal model with well developed, higher cortical } \\
\text { modulation of behaviour }\end{array}$ \\
\hline $\mathrm{HC} 2.5$ & $\begin{array}{l}\text { Fund work (experimental, literature review and crossdisciplinary discussion fora) that correlates measurement } \\
\text { systems used in animal models and in humans }\end{array}$ \\
\hline $\mathrm{HC} 2.6$ & $\begin{array}{l}\text { Fund research that aims to establish an integrated package of baseline data in SCI patients, including } \\
\text { comprehensive, sensitive and detailed characterisations of the state of spinal cord damage, synaptic connectivity and } \\
\text { residual function }\end{array}$ \\
\hline HC2.7 & $\begin{array}{l}\text { Fund work to identify human SCI subtypes using noninvasive parameters, including imaging, and correlate the } \\
\text { results with classical means of characterising subtypes by post-mortem morphological studies }\end{array}$ \\
\hline HC2.8 & $\begin{array}{l}\text { Fund studies of existing standardised methods for assessing residual function in SCI patients to estimate their } \\
\text { progression with time post-SCI, their intrinsic variability during longitudinal studies, and their sensitivity to different } \\
\text { degree of SCI (and therefore, their ability to track partial repair) }\end{array}$ \\
\hline HC2.9 & $\begin{array}{l}\text { Fund longitudinal studies of the new integrated package of methods for assessing function and connectivity in } \\
\text { patients to estimate their progression with time post-SCI, their intrinsic variability, and their sensitivity to different } \\
\text { degrees of SCI (and, therefore, their ability to track partial repair) }\end{array}$ \\
\hline
\end{tabular}

Table 10 Horizontal capability 3: Clinical trials

\begin{tabular}{ll}
\hline HC3.1 & $\begin{array}{l}\text { Initiate a forum in which current capabilities and gaps in knowledge are accurately identified and cooperative } \\
\text { approaches to improving these limitations as they affect SCI research and clinical trials are explored }\end{array}$ \\
HC3.2 & $\begin{array}{l}\text { Design and promote meaningful experimental protocols for clinical trials by engaging the cooperation of relevant } \\
\text { experts }\end{array}$ \\
HC3.3 & $\begin{array}{l}\text { Promote the exchange of insights between clinical, translational and basic research communities. Encourage the } \\
\text { consideration of basic scientific advances from the perspective of their potential clinical impact, and the exploration } \\
\text { of key clinical problems through appropriately designed lab studies, including the organisation of joint scientist- } \\
\text { clinician discussion meetings }\end{array}$ \\
HC3.4 & $\begin{array}{l}\text { Consider promoting SCI (if an appropriately robust clinical trial can be developed and tested) as a surrogate for } \\
\text { evaluating treatments for allied neurological applications, as a means of accessing additional support and potential } \\
\text { treatments }\end{array}$ \\
HC3.5 & $\begin{array}{l}\text { Explore options for sharing with other medical charities, especially in the neurosciences, additional staff to manage } \\
\text { clinical trial activities on a day-to-day basis }\end{array}$ \\
HC3.6 & $\begin{array}{l}\text { Establish links with other organisations to share knowledge and establish common standards of clinical and ethical } \\
\text { practice, including open access to databases }\end{array}$ \\
HC3.7 & $\begin{array}{l}\text { Define which specific types of SCI are suitable for various compounds, drugs, interventions and treatments } \\
\text { Promote organisations in which the establishment and conduct of a clinical trial protocol and follow-up studies are } \\
\text { possible. These centres of excellence should include facilities for baseline and follow up protocols, including }\end{array}$ \\
functional imaging and new interventional techniques
\end{tabular}

Many SCI and other relevant (eg regulatory) communities who participated considered whether standards and guidelines for valid clinical trials could be developed and broadly accepted. One of the outcomes of this is the establishment of a working group to bring forward detailed guidelines on how to develop clinical trials in the most accurate and effective manner. Clearly, several of the issues relate to the adequacy of the animal model that is used as the platform from which to launch a clinical trial ${ }^{74}$ (Table 10 and Horizontal capability 1).
As a more general consideration, Research Governance applies to all who fund research proposals or infrastructure, participate in research, and host research in their organisation. This is the process that sets standards and defines the mechanisms to deliver these, requires monitoring and assessment, and improves research quality and safeguards the public by enhancing ethical and scientific quality, promoting good practice, and preventing poor performance and misconduct. As an integral part of ensuring the highest clinical 
Table 11 Horizontal capability 4: Promoting collaborative research

\begin{tabular}{ll}
\hline HC4.1 & $\begin{array}{l}\text { Establish 'hub and spoke' organisations in which broad basic science and clinical knowledge is gathered in specific } \\
\text { centres }\end{array}$ \\
HC4.2 & Fund research fellowship for a combined basic and clinical researcher \\
HC4.3 & Support cross-disciplinary discussions and workshops between basic scientists, clinical scientists and clinicians \\
HC4.4 & $\begin{array}{l}\text { Establish links with laboratories and companies that are developing interventions that might be new treatments for } \\
\text { SCI, and with other supportive organisations. Promote the sharing of novel reagents between laboratories, including } \\
\text { commercial organisations } \\
\text { EC4.5 }\end{array}$ \\
& $\begin{array}{l}\text { Excourage interaction and the exchange of information and experiences between the SCI community and others, for } \\
\text { example, the use of immature or stem cells in other body systems such as cardiology and haematology }\end{array}$ \\
\hline
\end{tabular}

standards, ISRT must ensure that its governance structures are appropriate to achieve the aims of its Research Strategy.

\section{Horizontal capability 4}

\section{Promoting collaborative research}

The complexity of SCI in humans is such that multidisciplinary approaches are needed to understand SCI and to develop effective therapies to treat it. It is generally accepted that there is a need to continue to improve communication between the different groups involved in spinal cord injury research. Therefore, ISRT regards collaboration as one of the keys to future development (Table 11). To this end, it encourages collaborations between the researchers it funds, both clinical and basic scientists.

It is important for scientists to understand the general and specific problems associated with SCI research and ISRT accepts that it might be necessary to foster the training and career progression of a new 'breed' of clinical scientist to coordinate efforts and lead clinical trials in SCI. Such individuals should be familiar with basic science and have clinical knowledge, experience and training in the design, execution and evaluation of clinical trials. They should also be able to evaluate research strategies from the perspectives of SCI patients and other clinicians. This is important because what might appear to be an exciting solution to a basic scientist might have limited potential for translation to the clinic because of gaps in understanding between basic researchers and practising clinicians.

A single centre where different experts, such as basic and clinical scientists and clinicians who treat SCI patients easily interact is probably most effective. From such a hub, a spoke organisation should be established to exchange information, techniques and compounds with other units, and to coordinate with other centres to enable sufficient patients to be assessed in an appropriate time.

In addition, collaboration between basic researchers and clinicians should help to evaluate the course of neuronal function after a complete SCI and, consequently, to better understand neuronal plasticity and degradation. This would include the contributions of the different factors in determining the severity of functional loss after SCI, such as demyelination and neuronal loss at the lesion site, and link them to therapeutic approaches. An example might be the maintenance of neuronal function below the lesion by specific, earlyonset, functional training. ${ }^{75,76}$

Contacts or collaborations outside SCI research should also be encouraged to make use of existing knowledge of specific intended treatments and to ensure that mistakes are not repeated. For example, knowledge on the use of immature cells (eg stem cells) is more advanced in other areas of research such as haematology and cardiology, and this should be explored.

Collaborations with industry should be encouraged, both for support and as a source of new drugs and combinatorial therapies, and as a means of promoting international meetings where a wide spectrum of different aspects of SCI is discussed.

\section{Conclusions}

This latest Research Strategy from the ISRT builds on the previously published strategies ${ }^{1,2}$ by incorporating many of the most recent advances in basic and clinical research that are relevant to restoration of function following spinal cord injury. From past experience, identifying individual themes of basic and clinical research enables ISRT to focus research funding towards appropriate areas that would benefit from particular attention, and targeting specific research areas in this way has proved effective in maximising the effects of the available funding. As a research-based charity, ISRT intends grant applications to be influenced directly by the themes described in this strategy document. However, this is not to say that other, more novel approaches will not be considered should there be sufficiently strong evidence of their potential.

In keeping with the policy of promoting debate between all interested parties, another purpose of the updated ISRT Research Strategy is to stimulate discussion of the relative merits of the themes and approaches that are described. The Research Strategy is deliberately wide-ranging and inclusive with respect to the themes described, and individual views on the relative importance of these approaches are likely to differ. By promoting this discussion, ISRT hopes to encourage debate between scientists, clinicians, patients and other interest groups about the many issues that are involved in developing and validating potentially effective therapeutic advances in the near future. 


\section{References}

1 Harper GP, Banyard PJ, Sharpe PC. The International Spinal Research Trust's strategic approach to the development of treatments for the repair of spinal cord injury. Spinal Cord 1996; 34: 449-459.

2 Ramer MS, Harper GP, Bradbury EJ. Progress in spinal cord research: a refined strategy for the international spinal research trust. Spinal Cord 2000; 38: 449-472.

3 McDonald JW, Sadowsky C. Spinal-cord injury. Lancet 2002; 359: 417-425.

4 Profyris C, Cheema SS, Zang D, Azari MF, Boyle K, Petratos S. Degenerative and regenerative mechanisms governing spinal cord injury. Neurobiol Dis 2004; 15: 415-436.

5 Ramer LM, Ramer MS, Steeves JD. Setting the stage for functional repair of spinal cord injuries: a cast of thousands. Spinal Cord 2005; 43: 134-161.

6 Bracken MB et al. Methylprednisolone or tirilazad mesylate administration after acute spinal cord injury: 1-year follow up. Results of the third National Acute Spinal Cord Injury randomized controlled trial. J Neurosurg 1998; 89: 699-706.

7 Geisler FH, Coleman WP, Grieco G, Poonian D. The Sygen multicenter acute spinal cord injury study. Spine 2001; 26: S87-S98.

8 Stirling DP et al. Minocycline treatment reduces delayed oligodendrocyte death, attenuates axonal dieback, and improves functional outcome after spinal cord injury. J Neurosci 2004; 24: 2182-2190.

9 Leker RR, Shohami E. Cerebral ischemia and traumadifferent etiologies yet similar mechanisms: neuroprotective opportunities. Brain Res Brain Res Rev 2002; 39: 55-73.

10 Wahlgren NG, Ahmed N. Neuroprotection in cerebral ischaemia: facts and fancies - the need for new approaches. Cerebrovasc Dis 2004; 17: 153-166.

11 Anderson PN, Campbell G, Zhang Y, Lieberman AR. Cellular and molecular correlates of the regeneration of adult mammalian CNS axons into peripheral nerve grafts. Prog Brain Res 1998; 117: 211-232.

12 Schwab ME, Thoenen H. Dissociated neurons regenerate into sciatic but not optic nerve explants in culture irrespective of neurotrophic factors. J Neurosci 1985; 5: 2415-2423.

13 Schnell L, Schwab ME. Axonal regeneration in the rat spinal cord produced by an antibody against myelinassociated neurite growth inhibitors. Nature 1990; 343: 269-272.

14 Chen MS et al. Nogo-A is a myelin-associated neurite outgrowth inhibitor and an antigen for monoclonal antibody IN-1. Nature 2000; 403: 434-439.

15 Bareyre FM, Kerschensteiner M, Raineteau O, Mettenleiter TC, Weinmann O, Schwab ME. The injured spinal cord spontaneously forms a new intraspinal circuit in adult rats. Nat Neurosci 2004; 7: 269-277.

16 McKeon RJ, Höke A, Silver J. Injury-induced proteoglycans inhibit the potential for laminin-mediated axon growth on astrocytic scars. Exp Neurol 1995; 136: 32-43.

17 Bradbury EJ et al. Chondroitinase ABC promotes functional recovery after spinal cord injury. Nature 2002; 416: 636-640.

18 Bundesen LQ, Scheel TA, Bregman BS, Kromer LF. Ephrin-B2 and EphB2 regulation of astrocyte-meningeal fibroblast interactions in response to spinal cord lesions in adult rats. J Neurosci 2003; 2: 7789-7800.
19 Willson CA, Miranda JD, Foster RD, Onifer SM, Whittemore SR. Transection of the adult rat spinal cord upregulates EphB3 receptor and ligand expression. Cell Transplant 2003; 12: 279-290.

20 Pasterkamp RJ et al. Expression of the gene encoding the chemorepellent semaphorin III is induced in the fibroblast component of neural scar tissue formed following injuries of adult but not neonatal CNS. Mol Cell Neurosci 1999; 13: 143-166.

21 Filbin MT. Myelin-associated inhibitors of axonal regeneration in the adult mammalian CNS. Nat Rev Neurosci 2003; 4: 703-713.

22 Grill R, Murai K, Blesch A, Gage FH, Tuszynski MH. Cellular delivery of neurotrophin-3 promotes corticospinal axonal growth and partial functional recovery after spinal cord injury. J Neurosci 1997; 17: 5560-5572.

23 Ramer MS, Priestley JV, McMahon SB. Functional regeneration of sensory axons into the adult spinal cord. Nature 2000; 403: 312-316.

24 Lu P, Jones LL, Snyder EY, Tuszynski MH. Neural stem cells constitutively secrete neurotrophic factors and promote extensive host axonal growth after spinal cord injury. Exp Neurol 2003; 181: 115-129.

25 Bareyre FM, Schwab ME. Inflammation, degeneration and regeneration in the injured spinal cord: insights from DNA microarrays. Trends Neurosci 2003; 26: 555-563.

26 Geller HM, Fawcett JW. Building a bridge: engineering spinal cord repair. Exp Neurol 2002; 174: 125-136.

27 King VR, Henseler M, Brown RA, Priestley JV. Mats made from fibronectin support oriented growth of axons in the damaged spinal cord of the adult rat. Exp Neurol 2003; 182: $383-398$.

28 de Wit J, Verhaagen J. Role of semaphorins in the adult nervous system. Prog Neurobiol 2003; 71: 249-267.

29 Gallo G, Letourneau PC. Regulation of growth cone actin filaments by guidance cues. J Neurobiol 2004; 58: 92-102.

30 Skaper SD, Moore SE, Walsh FS. Cell signalling cascades regulating neuronal growth-promoting and inhibitory cues. Prog Neurobiol 2001; 65: 593-608.

31 Noga BR, Kriellaars DJ, Jordan LM. The effect of selective brainstem or spinal cord lesions on treadmill locomotion evoked by stimulation of the mesencephalic or pontomedullary locomotor regions. J Neurosci 1991; 11: 1691-1700.

32 Nathan PW. Effects on movement of surgical incisions into the human spinal cord. Brain 1991; 117: 337-346.

33 Blight AR. Cellular morphology of chronic spinal cord injury in the cat: analysis of myelinated axons by linesampling. Neuroscience 1983; 10: 521-543.

34 Eidelberg E, Story JL, Walden JG, Meyer BL. Anatomical correlates of return of locomotor function after partial spinal cord lesions in cats. Exp Brain Res 1981; 42: 81-88.

35 Hofstetter CP et al. A review of the neuropathology of human spinal cord injury with emphasis on special features. J Spinal Cord Med 1999; 22: 119-124.

36 Maegele M, Muller S, Wernig A, Edgerton VR, Harkema SJ. Recruitment of spinal motor pools during voluntary movements versus stepping after human spinal cord injury. J Neurotrauma 2002; 19: 1217-1229.

37 Dietz V. Proprioception and locomotor disorders. Nat Rev Neurosci 2002; 10: 781-790.

38 Dietz V, Muller R, Colombo G. Locomotor activity in spinal man: significance of afferent input from joint and load receptors. Brain 2002; 125: 2626-2634.

39 Wolpaw JR. Spinal Cord Plasticity: Alterations in Reflex Function. Kluwer Academic Publishers: Boston 2001. 
40 Holler M, Hopf HC. Posttraumatic synkinesis of the diaphragm and muscles of the brachial plexus. Deut Zeit Nervenheilkund 1968; 193: 141-153.

41 Robinson PK. Associate movements between limb and respiratory muscles as a sequel to brachial plexus birth injury. Bull Johns Hopkins Hosp 1951; 89: 21-29.

42 Kew JJ et al. Abnormal access of axial vobrotactile input to deafferentated somatosensory cortex in human upper limb amputees. J Neurophysiol 1997; 77: 2753-2764.

43 Moore CI et al. Referred phantom sensation and cortical reorganisation after spinal cord injury in humans. Proc Natl Acad Sci USA 2000; 97: 14703-14708.

44 Banati RB. Brain plasticity and microglia: is transsynaptic glial activation in the thalamus after limb denervation linked to cortical plasticity and central sensitisation? J Physiol Paris 2002; 96: 289-299.

45 Jain N, Florence SL, Kaas JH. Reorganisation of somatosensory cortex after nerve and spinal cord injury. News Physiol Sci 1998; 13: 143-149.

46 Moore KA, Kohno T, Karchewski LA, Scholz J, Baba H, Woolf CJ. Partial peripheral nerve injury promotes a selective loss of GABAergic inhibition in the superficial dorsal horn of the spinal cord. J Neurosci 2002; 22: 6724-6731.

47 Turton AJ, Butler SR. Referred sensations following stroke. Neurocase 2001; 7: 397-405.

48 Borsook D et al. Acute plasticity in the human somatosensory cortex following amputation. Neuroreport 1998; 9: 1013-1017.

49 Kaas JH, Merzenich MM, Killackey HP. The reorganisation of somatosensory cortex following peripheral nerve damage in adult and developing mammals. Ann Rev Neurosci 1983; 6: 325-356.

50 Vroemen M, Aigner L, Winkler J, Weidner N. Adult neural progenitor cell grafts survive after acute spinal cord injury and integrate along axonal pathways. Eur $J$ Neurosci 2003; 18: 743-751.

51 Hill CE et al. Acute transplantation of glial-restricted precursor cells into spinal cord contusion injuries: survival, differentiation, and effects on lesion environment and axonal regeneration. Exp Neurol 2004; 190: 289-310.

52 Hofstetter CP et al. Allodynia limits the usefulness of intraspinal neural stem cell grafts; directed differentiation improves outcome. Nat Neurosci 2005; 8: 346-353.

53 Akiyama Y, Radtke C, Kocsis JD. Remyelination of the rat spinal cord by transplantation of identified bone marrow stromal cells. J Neurosci 2002; 22: 6623-6630.

54 Hofstetter CP et al. Marrow stromal cells form guiding strands in the injured spinal cord and promote recovery. Proc Natl Acad Sci USA 2002; 99: 2199-2204.

55 Ankeny DP, McTigue DM, Jakeman LB. Bone marrow transplants provide tissue protection and directional guidance for axons after contusive spinal cord injury in rats. Exp Neurol 2004; 190: 17-31.

$56 \mathrm{Lu}$ P, Jones LL, Tuszynski MH. BDNF-expressing marrow stromal cells support extensive axonal growth at sites of spinal cord injury. BDNF-expressing marrow stromal cells support extensive axonal growth at sites of spinal cord injury. Exp Neurol 2005; 191: 344-360.

57 Kamada T et al. Transplantation of bone marrow stromal cell-derived Schwann cells promotes axonal regeneration and functional recovery after complete transection of adult rat spinal cord. J Neuropathol Exp Neurol 2005; 64: 37-45.

58 Neuhuber B, Timothy Himes B, Shumsky JS, Gallo G, Fischer I. Axon growth and recovery of function supported by human bone marrow stromal cells in the injured spinal cord exhibit donor variations. Brain Res 2005; 1035: 73-85.

59 Barnett SC. Olfactory ensheathing cells: unique glial cell types? Neurotrauma 2004; 21: 375-382.

60 Raisman G. Olfactory ensheathing cells and repair of brain and spinal cord injuries. Cloning Stem Cells 2004; 6: 364-368.

61 Fouad K, Schnell L, Bunge MB, Schwab ME, Liebscher T, Pearse DD. Combining Schwann cell bridges and olfactory-ensheathing glia grafts with chondroitinase promotes locomotor recovery after complete transection of the spinal cord. J Neurosci 2005; 25: 1169-1178.

62 Blits B et al. Rescue and sprouting of motoneurons following ventral root avulsion and reimplantation combined with intraspinal adeno-associated viral vectormediated expression of glial cell line-derived neurotrophic factor or brain-derived neurotrophic factor. Exp Neurol 2004; 189: 303-316.

63 Ruitenberg MJ et al. Adeno-associated viral vectormediated gene transfer of brain-derived neurotrophic factor reverses atrophy of rubrospinal neurons following both acute and chronic spinal cord injury. Neurobiol Dis 2004; 15: 394-406.

64 Ruitenberg MJ, Hendriks WJT, Boer GJ, Verhaagen J. Gene therapy for spinal cord injury. In: Kaplitt $\mathrm{MG}$, During M (eds). Gene Therapy in the Central Nervous System. Elsevier Inc.: Amsterdam 2006. pp 273-288.

65 Gaunt RA, Prochazka A. Control of urinary bladder function with devices: successes and failures. Prog Brain Res 2006; 152: 163-194.

66 Prochazka A, Mushahwar VK, McCreery DB. Neural prostheses. J Physiol 2001; 533: 99-109.

67 Balsubramanian AV, Wood S, Middleton FRI, Fowler C, Craggs MD. Urinary guarding reflex: aberrant in spinal cord injury? Br J Urol Int 2004; 9: 4.

68 Balsubramanian AV, Craggs MD, Fowler CJ. A neurophysiological and urodynamic assessment of residual supra-sacral sensory-motor pathways and their influence on aberrant lumbar-sacral reflexes in incomplete spinal cord injury. ISRT Annu Res Rev 2004; 9: 111-115.

69 Rodi Z, Vodusek DB. The sacral reflex studies:single versus double pulse electrical stimulation. Neurourol Urodyn 1995; 14: $496-497$.

70 Curt A, Dietz V. Electrophysiological recordings in patients with spinal cord injury: significance for predicting outcome. Spinal Cord 1999; 37: 157-165.

71 Marshall LF et al. Deterioration following spinal cord injury. A multicenter study. J Neurosurg 1987; 66: 400-404.

72 Granovsky Y, Matre D, Sokolik A, Lorenz J, Casey KL. Thermoreceptive innervation of human glabrous and hairy skin: a contact heat evoked potential analysis. Pain 2005; 115: $238-247$.

73 Steeves J, Fawcett J, Tuszynski M. Report of international clinical trials workshop on spinal cord injury February 20-21, 2004, Vancouver, Canada. Spinal Cord 2004; 42: 591-597.

74 Christopher Reeve Foundation. Can non-human primate experiments expedite translation of potential regenerative interventions following spinal cord injury to humans? in revision.

75 Edgerton VR, Roy RR, Hodgson JA, Prober RJ, de Guzman CP, de Leon R. Potential of adult mammalian lumbosacral spinal cord to execute and acquire improved locomotion in the absence of supraspinal input. J Neurotrauma 1992; 9: S119-S128.

76 Dietz V, Harkema SJ. Locomotor activity in spinal cordinjured persons. J Appl Physiol 2004; 96: 1954-1960. 